\title{
Putting Popper to work
}

Accepted for publication in special issue of Theory \& Psychology on Psychology's Epistemic Project, edited by Estrid Sørensen and Lotte Huniche. Please do not quote without permission.

Maarten Derksen

Theory \& History of Psychology

University of Groningen

It is a feature of the reform movement that is sweeping through psychology at the moment that it is explicitly inspired by philosophy of science, the work of Karl Popper in particular. References to Popper and like-minded philosophers of science such as Paul Meehl are used to support arguments about what science is, what has caused the current problems, and how they should be solved." The reform movement is an epistemic project that is informed by epistemology. This would have pleased Popper, who wrote, in the preface to the English edition of The Logic of Scientific Discovery, that the theory of knowledge, including his own, aims to "enable us not only to know more about knowledge, but also to contribute to the advance of knowledge - of scientific knowledge that is." (Popper, 1972, p. xxiii)

This development may amuse those who, like me, have taken on board the lessons of the empirical turn in the study of science. One of those lessons after all was that science does not work the way Karl Popper thought it should. When sociologists of science in the 1970s entered the laboratories to study the actual process of science they discovered that it doesn't follow the rules that Popper, or any other philosopher of science for that matter, had laid down. Research is messy, researchers are motivated by more than a desire for objective truth, and facts are not discovered but constructed in a process that involves many more actors than those allowed by traditional philosophers of science. When Bruno Latour was asked (in an interview on Dutch television) whether science proceeds by falsification, he laughed derisively and answered: “That is the textbook version of science, I don't think there is any case where this works as nicely as this." (Schepens, 1994 at 14:15) However, as much as we post-Kuhnian students of science might be tempted to dismiss the 
psychology reformers as naive, our first step should be to study this development empirically, including the role Popper's ideas play in it.

Michael Mulkay and Nigel Gilbert were here before us. In their article 'Putting Philosophy to Work: Karl Popper's Influence on Scientific Practice' (Mulkay \& Gilbert, 1981) they reported on interviews they had conducted with biochemists in the context of their study of a controversy in that field (see also N. Gilbert \& Mulkay, 1984). These researchers regularly mentioned Popper, even though they never referred to him in their primary literature. What was the role of Popper's ideas in their own thinking and research? What work did Popper do for them? It became clear from the interviews that the rules that Popper had formulated did not function to constrain action. Even the interviewees who identified as Popperians acknowledged that they did not look to Popper's methodological rules as prescriptions for their day to day laboratory work. Rather, Popper was used as an evaluative resource, a way to say 'good' and 'bad' after the fact. Popper's philosophy of science was used to describe what was good about a particular study or researcher, but not to determine how to proceed in doing research.

Mulkay and Gilbert saw a fundamental truth about rules reflected here: the relationship between rules and practice is "essentially indeterminate" (Mulkay \& Gilbert, 1981, p. 404). Rules do not determine their own application. Following a rule always requires an interpretation of what the rule means in this particular situation. In science, the gap between rules and action is particularly wide because at the forefront of research novel situations are being created: new techniques, new instruments, and of course new phenomena and effects, which all raise the question how the rules apply in these novel circumstances. For example, Popper had argued that one cannot verify a theory, one can only disprove it. Thus falsifiability is the mark of a scientific theory, and science should proceed by attempts at falsification. That is clear enough. However, Mulkay and Gilbert noted that whether or not a particular experimental result is a falsification depends on a technical, scientific appraisal of the experiment. In situations of scientific uncertainty, in new lines of research, such appraisals will vary between researchers. "Consequently, when there is uncertainty, the Popperian rules cannot provide a straightforward guide for scientists' actions or 
decisions. There is a gap between rule and particular action which can only be bridged by the very scientific choice which the rule is intended to constrain." (Mulkay \& Gilbert, 1981, p. 398)

Popper's work does not provide any guidance for how to deal with this interpretative challenge. His rules of method were based on the rational reconstruction of scientific achievements, rather than on a description of actual scientific practice. From this hindsight perspective the interpretative work that was required in scientific practice becomes invisible. As a result this (or indeed any) prescriptive philosophy of science on its own can give little guidance for this work. Popper "remains unclear about the connection between the formal analysis of scientific belief systems and the provision of rules of action; and (...) he hasn't considered in detail how his rules of scientific method are to be put into practical effect." (Mulkay \& Gilbert, 1981, p. 392) To tighten the link between prescription and action, Mulkay and Gilbert argue, the rules must become embodied in a social practice, "so that potential actors have access to a corpus of exemplary instances, they are guided in their efforts by skilled interpreters, and they are subject to various kinds of direct control" (Mulkay \& Gilbert, 1981, p. 407).iii Rules will never determine action unambiguously, but they can be made more effective through the intrepretative work of a community of researchers, who translate general methodological rules (such as 'always expose your theories to the possibility of refutation') into more specific directions for what should be done with regard to this specific hypothesis and others of its kind, who negotiate difficult cases, draw up guidelines, and sanction those who contravene them.

The same question that Mulkay and Gilbert asked thirty-six years ago is relevant today with regard to the current reformers in psychology: how do these psychologists put Popper to work? The history of science studies following Mulkay and Gilbert's paper has given this question added poignancy. In 1981 Popper's influence was still great (and he was still alive), and their generation of sociologists of science partly defined itself in relation to his work: by turning Popper on his head, for example, as in this paper, and investigating how norms work in practice. Since then Popper has gradually receded from 
view in science studies, no longer relevant, even as a foil. What then should we make of this apparent renaissance of Popperian thinking in psychology?

\section{Philosophy in practice}

Ever since the reform movement in psychology began to coalesce in 2011 , replicability has been its main concern. ${ }^{i v}$ The frequency with which even high-profile studies fail to replicate is seen as an indication of fundamental problems in the usual research practices of the discipline. A lack of transparency is seen as a major cause of the problems: a lack of disclosure about the actual research process and its results allows researchers to present their studies in a favourable but misleading way and keeps null results ('failed experiments') in the file drawer. As a result, the discipline's archive may look like a corpus of scientific success stories, but it is actually "a vast graveyard of undead theories" (Ferguson \& Heene, 2012).

In the proposals for improvement that have been appearing regularly over the past six years statements about 'what science is' have an important place. ${ }^{v}$ In contrast to Mulkay and Gilbert's biochemists, ${ }^{\text {vi }}$ quite a number of these reformers in psychology read philosophy of science. For instance, a recent blog post in which the author argued that null hypothesis significance testing is compatible with Popper's ideas about falsification, mentioned Duhem, Lakatos, Laudan, Van Fraassen and Feyerabend as well as Popper (Lakens, 2017a). Another example: Zoltán Dienes' Understanding Psychology as a Science, a textbook that leans heavily on Popper, is enthusiastically recommended as summer reading (Lakens, 2017b; Srivastava, 2017). Even when Popper is not mentioned, science is depicted in a way that largely conforms to his philosophy of science, in that falsifiability, falsification, and replication are seen as crucial elements of the scientific process. Reformers emphasise that scientific theories must be falsifiable. Mostly this is presented as self-evident, but sometimes Popper is referred to (e.g. LeBel \& Peters, 2011, p. 373). Falsifaction, the reformers believe, "is achieved via meticulously executed series of direct replications" (LeBel, 2017 emphasis in original), that is to say by following the procedure of the original experiment as closely as possible. In this context, the reformers like to quote from section 8 of Popper's 
Logic of Scientific Discovery, where he states that observations are only intersubjectively testable when they can be repeated by following specific instructions. The upshot is, in the words of one prominent reformer, "that (1) scientists should replicate their own experiments; (2) scientists should be able to instruct other experts how to reproduce their experiments and get the same results; and (3) establishing the reproducibility of experiments ('direct replication' in the parlance of our times) is a necessary precursor for all the other things you do to construct and test theories." (Srivastava, 2014b)

Whereas Popper was primarily an evaluative resource for Mulkay and Gilbert's biochemists, these psychologists translate Popper's philosophy of science into a program of reform, with concrete rules of practice, an infrastructure for that practice, and research projects that realise the ideal. The rules and requirements focus, first of all, on restraining the so-called 'researcher degrees of freedom', a term coined by Simmons, Nelson and Simonsohn for the leeway that researchers have in the decisions they take for the collection and analysis of their data (Simmons, Nelson, $\&$ Simonsohn, 2011). Hypothesis testing requires such decisions - sample size, exclusion of outliers, which comparisons to make, etcetera - to be taken before data collection begins, but it is common practice, Simmons et al. noted, to explore various possibilities during data analysis, see which combination produces statistical significance, and only report that result. Another problematic practice, not discussed by Simmons et al. in their paper, is to fit the hypothesis to the data and create a significant result that way, a process known as HARKing: hypothesizing after results are known (Kerr, 1998). In all these cases, one is not testing (i.e. attempting to falsify) hypotheses, but generating hypotheses from the data.

The most commonly proposed solution to this problem is pre-registration, where researchers create a detailed plan for data collection and analysis and upload it to a repository, where it gets a date stamp (see e.g. Bishop, 2013; Eric-Jan Wagenmakers, Wetzels, Borsboom, Maas, \& Kievit, 2012). Once the study is completed, other researchers can consult the repository to see whether the study actually followed the registered research plan. Of course, 
this system can be gamed by registering multiple plans, but that would require intentional bad faith rather than sloppy or questionable research practice.

A related initiative are the registered reports (RR), a publication option devised by Chris Chambers (2013), editor of Cortex, and now offered by an increasing number of journals in psychology and other disciplines. In an RR, a researcher submits a proposal for a study to a journal, including a detailed plan for data collection and analysis. Reviewers then look at the relevance and importance of the question and the quality of the research plan, and if the proposal is accepted publication of the final report is guaranteed regardless of the outcome of the study, provided the research plan has been followed. The RR procedure combines the advantage of pre-registration with the guarantee that null results will also be published, thus increasing the chance that theories are (recognised to have been) falsified. Moreover, registered reports are often offered as a publication option for direct replication studies (RRR, registered replication reports).

Pre-registration and registered reports are presented as enforcing a distinction between 'exploratory' and 'confirmatory' research, between generating hypotheses and testing them. Both are important, it is emphasised, but testing has to be separate from exploration to properly count as such (e.g. Bishop, 2013; C. Chambers, 2017a; Neuroskeptic, 2013). Thus, pre-registration and registered reports give an administrative guarantee that what is presented as the test of a prediction was indeed an attempt to falsify a hypothesis and not actually an inductive process of developing theory from data. In contrast to Popper, these reformers explicitly give induction a place in the scientific process, but on condition that it remains strictly separate from "purely confirmatory research" (Eric-Jan Wagenmakers et al., 2012). It's clear moreover that whereas exploration is acknowledged as important, hypothesis testing is considered necessary: without it there is no science.

\section{Social engineering}

To Popper, the rules of method that he proposed in The Logic of Scientific Discovery were the application to science of a more general conception of reason that he called critical rationalism. In The Logic of Scientific Discovery 
and even more in The Open Society and its Enemies Popper emphasised that scientific objectivity is not the result of the attitude or efforts of individual scientists, but rather the "product of the social or public character of the scientific method" (Popper, 2002b, p. 491). The rational route to objectivity is openness and "friendly-hostile co-operation" (Popper, 2002b, p. 489). In line with this ideal, the reform movement pursues transparency in all stages of the research process and it has a penchant for vigorous discussion. Equally in line with Popper's recommendations, it tries to institutionalise these values. Critical rationalism, Popper wrote, implies the necessity of creating institutions that protect "freedom of criticism, freedom of thought" (Popper, 2002b, p. 511). It "establishes something like a moral obligation" to engage in "practical social engineering" (ibidem). Although The Open Society and its Enemies is seldom referred to, the reform movement is doing exactly what Popper thought was necessary: not only does it make enthusiastic use of social media to conduct its 'friendly-hostile' discussions, but it is also engineering its own socialtechnological infrastructure to enable transparency, collaboration, and replication.

A particularly successful initiative is the Open Science Framework (OSF, https://osf.io/), an online platform developed and maintained by the Center for Open Science (COS), founded by social psychologists Brian Nosek and Jeffrey Spies. The OSF facilitates the kind of open, reproducible science that the reformers advocate. Via the OSF researchers can pre-register their studies, share materials, store and share data, and collaborate with others. The goal is to make the entire research process transparent, and thus also eminently reproducible. The OSF has hosted a number of replication projects that were started by reformers to put their ideas about replication and falsification in practice. The best known of these was a mammoth collaborative effort to replicate 100 studies from one volume of three psychological journals. Working together in the 'Open Science Collaboration' were 269 researchers, mainly from North America and Europe. The results were alarming: according to the team's assessment, only 39 replication attempts succeeded (Collaboration, 2015). vii The OSF has also hosted several so-called 'Many Labs' projects, in which a small number of original studies are each replicated by a number of research 
teams, to see whether replication success depends on contextual factors such as the nationality of the participants (Klein et al., 2014) or the semester in which students participate in studies (Ebersole et al., 2016). Neither factor appeared to have much influence on whether the original result could be reproduced. Thus, the Many Labs projects had produced evidence against contextual moderators as explanations for replication failure (Srivastava, 2015).

The internet is the reform movement's primary habitat. Blogs are popular outlets for ideas and commentary; blog posts are typically announced on Twitter and Facebook, and then further discussed there, often leading to new blog posts. Web-based platforms like the OSF not only facilitate collaboration but also serve to share preprints (https://osf.io/preprints/psyarxiv), following the example of the successful physics preprint repository arXiv. Such online platforms and social media allow fast, free dissemination of ideas, results, and papers, followed by virtually instant, open discussion and critique, often leading to follow-up collaborative projects to test new hypotheses. Bobbie Spelman has argued that replication studies could only become such an important factor in the crisis because news about them spreads quickly over the internet, whereas before one would typically learn about a failure to replicate, if at all, in a "fortuitous late night conference conversation" (Spellman, 2015, p. 888). The online world, moreover, is one where traditional gatekeepers such as editors and reviewers are much less powerful because anyone can be an editor publish their own blog, for example - and a reviewer - for instance on PubPeer, the "online journal club" where anyone can post comments on any scientific article (https://pubpeer.com). The social practice characterised by transparency and mutual criticism which the reform movement is creating embodies Popper's critical rationalism. A kind of Popperian Open Society is in the making, an Open Psychology, where everything may be subjected to criticism by anyone, and tradition and reputation hold no sway.

\section{Controversy}

This budding community of practice is not without its detractors, however. Open Psychology is resisted by a number of social psychologists in 
particular, who object to what they consider unfair criticism of the status quo, to the way this criticism is expressed, and to the emphasis on direct replication as a sine qua non of science. ${ }^{\text {viii }}$ The discussion between reformers and counterreformers can turn quite heated, as was the case in the controversy in 2014 over the non-replication of a study by Simone Schnall and colleagues. It is worth looking at this controversy in some detail, because it shows how Popper is put to work by the reformers, and how his rules of method and his 'friendlyhostile co-operation' are resisted by others.

The original study had produced the kind of attention-grabbing result that the critics see as typical of the discipline's focus on novelty at the expense of rigour: people who feel clean offer milder judgements of moral transgressions. As the title put it: "cleanliness reduces the severity of moral judgements" (Schnall, Benton, \& Harvey, 2008). Schnall and colleagues described two experiments that had produced this effect. In the first, participants were first 'primed' with cleanliness by having them do a scrambled-sentences task. They had to construct three-word sentences out of sets of four words; in the experimental condition, half the sets contained words related to cleanliness, like pure, washed, and immaculate. After this task, the participants were asked to rate six morally loaded actions, including putting false information in your CV and using a kitten for sexual gratification. In the second experiment, participants were asked to wash their hands after watching a disgusting film clip, and then had to rate the vignettes. In both experiments, participants on average made less severe moral judgements in the experimental condition. In their replication study, Johnson and colleagues, using the same materials, almost identical procedures, and a much larger sample, failed to find any effect in either experiment (Johnson, Cheung, \& Donnellan, 2014).

A rather acrimonious debate ensued. ${ }^{i x}$ Schnall, supported by luminaries such as Daniel Kahneman (Kahneman, n.d.), Matthew Lieberman (2014) and Daniel Gilbert (2014), complained about the fact that she had not been allowed to review the final report of the replication (it was a Registered Report) (Schnall, 2014b). She also criticised the "crime control mindset" of the reform camp, which, she contended, tends to see every non-replication as an indication of problems in the original study (Schnall, 2014a), and then shames 
the original researcher in online media. A culture of "replication bullying" had emerged (Schnall, 2014b). One of the replicators, for example, had triumphantly called their study "an epic fail" (Donnellan, 2013). Rushing to Schnall's aid, Gilbert accused the "replication police" of being "shameless little bullies" (D. Gilbert, 2014).

But Schnall also raised questions regarding the value of replication studies per se, how they should be conducted, and by whom. She emphasised, first of all, that experimentation in social psychology is very difficult, much more complicated in fact than in hard sciences like physics. "There are always many reasons for a study to go wrong and everything would have to go right to get the effect." (Schnall, 2014a) Therefore, when people without expertise in a particular field of study fail to find the same effect in a replication, we shouldn't read too much into it. "(B)efore you declare that there definitely is no effect, the burden of proof has to be really high." (Schnall, 2014a) More generally, the current emphasis on 'direct replications' (Schnall preferred the term 'method replications') is misguided. In a complicated field like social psychology, we shouldn't expect a particular experiment to produce the same effect every time, even when the experiment is done by experts. Human social behavior is extremely sensitive to variations in the social and cultural context. Schnall noted, for example, that the participants in the replication study (students at an American university) had evaluated the vignettes much more negatively than the English students in the original study, leading to a ceiling effect in the dependent variable. The failed replication was most likely due to the relative moral laxness of English campus culture, she implied. Rather than putting so much weight on a failed direct replication, we should focus on conceptual replications, in which the same theory is tested with a different procedure. In fact, the connection between physical cleanliness and moral judgement had been conceptually replicated many times, Schnall insisted.

In response, proponents of direct replications argued that direct replication is a basic requirement in science, and supported this point with references to Popper. Personality psychologist Sanjay Srivastava for example argued that "every experimental report comes with its own repeatability theory", because each methods section implies that someone who follows the 
same procedure will get the same results (Srivastava, 2014a). This implicit mini-theory is eminently falsifiable, as long as we specify what will count as 'the same result' and we spell out the requirements of the experiment.

Schnall's argument that it is up to the replicating researchers to acquire the necessary expertise is wrong. "The onus is on the original experimenter to be able to tell a competent colleague what is necessary to repeat the experiment." (Srivastava, 2014a) And if they cannot, there is no reason to have any confidence in the original result. At this point, Srivastava gave a quote from Popper's The Logic of Scientific Discovery, which ends with the line: "No serious physicist would offer for publication, as a scientific discovery, any such 'occult effect,' as I propose to call it - one for whose reproduction he could give no instructions." (Popper, 2002a, p. 24) Andrew Wilson was scathing about Schnall's and Kahneman's insistence that the original researcher should always be consulted for a replication: "once you have published some work then it is fair game for replication, failure to replicate, criticism, critique and discussion. (...) We don't need either your permission or your involvement: the only thing we (should) need is your Methods section and if you don't like this, then stop publishing your results where we can find them." (Wilson, 2014)

Srivastava and other proponents of direct replication acknowledged that falsifying a substantial theory is more complicated than testing the mini-theory implied by the method section of a report. They admitted the problem noted by Quine and Duhem, that a theory is never tested in isolation but always in combination with a number of background assumptions, and endorsed Lakatos's amendments to Popper's methodology (Srivastava, 2014a). It all starts, however, with establishing the reproducibility of the phenomenon itself, and to this end we must do direct replications. "Only by such repetitions can we convince ourselves that we are not dealing with a mere isolated 'coincidence', but with events which, on account of their regularity and reproducibility, are in principle inter-subjectively testable." (Popper, 1972, p. 23) Were we to drop this requirement, "we would be doing history rather than science" (Srivastava, 2014a).

Similar replication controversies have occurred since the Schnall affair. ${ }^{x}$ Non-replications keep the debate about fundamental problems in psychology 
and their solution alive. The proponents of conceptual replication have begun to support their position with arguments drawn from philosophy of science as well. Chris Crandall and Jeff Sherman invoke Duhem and Quine to claim that the "'failure' of an empirical test is always ambiguous" (Crandall \& Sherman, 2016, p. 94). Conceptual replications, they say, "disperse this ambiguity, and as a result, can contribute more to theoretical development and scientific advance" (ibidem). In a similar vein, Wolfgang Stroebe has attempted to combine a commitment to falsificationism with a preference for conceptual replications. Direct replications are initially important for the original researcher to establish whether the effect is robust, but, given the context-sensitivity of social psychological phenomena, later non-replications do not tell us much. Instead the focus should shift to conceptual replications, and meta-analyses can determine whether the theory is corroborated or falsified. Psychological theories are not about actual phenomena, which are variable, but about the stable, universal mechanisms that underlie them. With a reference to Popper's Conjectures and Refutations, Stroebe argued that "theories are not refuted by a single inconsistent finding but by studies that support an alternative theory that has greater empirical content" (Stroebe, 2016, p. 143). The reformers respond that conceptual replications are certainly important to refine a theory and develop it further, but direct replications are fundamental. "(I)f a phenomenon is not replicable (i.e., it cannot be consistently observed), it is simply not possible to empirically pursue the other goals of science." (LeBel, Berger, Campbell, \& Loving, 2017, pp. 8-9). ${ }^{\mathrm{i}}$

How and where criticism should be delivered also remains a hotly debated issue. In September 2016 Susan Fiske wrote a brief guest column for the APS Observer, in which she attacked the way psychology's reformers were going about critiquing the work of others. A first version, which found its way online, contained terms like "trash-talk" and "methodological terrorism" (Fiske, 2016a). After predictable outrage from the critics, the text was toned down a bit for publication, but Fiske's point remained the same: the critics ("bullies") are promoting a culture of shaming, harassment, and unrestrained hostility, and it is making victims. "(C)olleagues at all career stages have reported leaving the field because of what they see as sheer adversarial viciousness." 
(Fiske, 2016b) She thought this culture of "uncurated, unfiltered denigration" is "encouraged by the new media (e.g. blogs, Twitter, Facebook)" (ibidem), where everyone can publish criticism, regardless of whether it is valid or appropriate. Fiske advocated a return to traditional fora, "with their rebuttals and letters-tothe-editor subject to editorial oversight and peer review for tone, substance, and legitimacy." (ibidem) In response, some of the critics posted a conciliatory petition "Promoting open, critical, civil, and inclusive scientific discourse in Psychology", which attracted 600 signatures ("Promoting Open, Critical, Civil, and Inclusive Scientific Discourse in Psychology," 2016), but the dominant opinion about Fiske's piece was that she was papering over the real problems in Psychology (e.g. Gelman, 2016; Yarkoni, 2016). Now, a year later, the 'tone debate' shows no sign of abating (C. Chambers, 2017b; Schwarzkopf, 2017), and increasingly includes issues of diversity (Hamlin, 2017; Ledgerwood, 2017).

\section{Rules and practices}

I have argued that the reform movement is guided by a Popperian view of how science should be conducted, both as to its methodological rules (replication and falsification in particular) and as to the general culture of openness, mutual criticism and collaboration in which it needs to be embedded. That is not to say that all aspects of Popper's work are represented in the discourse of the critics, ${ }^{\text {xii }}$ nor that they always name Popper as the source of their ideas about replication, falsification, and criticism, nor that there aren't non-Popperian or even anti-Popperian elements in their ideas. What I have shown is that the critics are trying to create a scientific practice that corresponds to Popper's philosophy of science in several key aspects, sometimes explicitly referring to and discussing his work and that of likeminded philosophers of science. In that sense they are putting philosophy of science, Popper in particular, to work.

What about the relation between rules and practice in these reforms? As I mentioned in the introduction, Mulkay and Gilbert based their analysis on the philosophical position that that relation is essentially indeterminate. " $(\mathrm{N})$ o rule can specify completely what is to count as following or not following that rule. The terms of a rule always need to be interpreted in relation to the variable 
characteristics of specific situations." (Mulkay \& Gilbert, 1981, p. 400) This conception of rules stems from a reading of Wittgenstein's discussion of rulefollowing in Philosophical Investigations. Philosopher Saul Kripke (1982) is its best-known representative. It is a skeptical reading that has been vigorously disputed in philosophy (Baker \& Hacker, 1985), as well as in science studies see for instance the discussion between Michael Lynch and David Bloor in Pickering (1992). In the nonskeptical view there is no essential gap between rule and practice, even though on occasion it may be unclear what rule applies and how. Interpretation, translating a rule to a specific situation, is sometimes required, but not 'always', as Mulkay \& Gilbert claimed. Following a rule is not the same as interpreting it. Usually we follow a rule blindly; if interpretation were constantly required it would cease to be a rule.

Even if we accept this nonskeptical view of rules, however, we may concede that the meaning of rules is more ambiguous, less self-evident in situations characterised by novelty and uncertainty. Mulkay and Gilbert argued that this is inherently the case in scientific research, where new techniques, instruments, and effects regularly raise the question how rules should be applied. In such circumstances, disambiguating the relation between methodological rules and scientific practice requires creating "interpretative procedures and social relationships" (Mulkay \& Gilbert, 1981, p. 404) (ibidem) to make Popper's methodological rules "effective as constraints" (1981, p. 407). Indeed such interpretative work is happening in the current debate, where every new failed replication instantly leads to fresh discussion about how this result should be interpreted, and whether it suggests further rules and procedures - the Schnall affair is typical in this regard. But the reformers do more than discuss the interpretation of methodological rules. Where Mulkay and Gilbert speak of a social practice that guides and controls the interpretation of rules, thus bridging the gap between rules and practice, what the reformers are trying to create goes further by giving these rules administrative form (pre-registration, Registered Reports) and creating infrastructure to facilitate an Open Psychology. The rule that scientific statements must be exposed to the risk of falsification is expressed in and as pre-registration, just as openness to criticism is expressed in and as the 
technology of the Open Science Framework. The rules are institutionalised and materialised, a process that I have compared to Popper's 'social engineering'.

At the same time it is clear that this is a work in progress, and the crisis is not over yet. Two issues remain particularly contentious, as I have shown. The first is the question how scientific debates should be conducted in the context of the new online collaboration and communication platforms. This is a context that is quite different from the one that Popper had in mind when he described his 'open society' and its 'friendly-hostile co-operation'. It is a technological landscape in which a pre-print (reporting, say, a failed replication of a classic experiment in psychology) can be made available to anyone with an internet connection and announced on Twitter, where it subsequently may be discussed by anyone with an account. Within hours opinions are formed and exchanged, counter-opinions appear, and soon a debate develops that needs only a slight exaggeration, an unfortunate phrase or a bad joke to spiral out of hand in the way that so many online conversations do. It is doubtful that a return to the classic mode of peer-reviewed discussion in scientific journals is the solution, as Susan Fiske thinks, or even likely as an option, but it is clear that academia in general is looking for a new ethics of academic debate in this online world. This too is a problem of interpretation: what does 'friendly-hostile co-operation' mean in this novel context? What does civility look like in a tweet, or in a blog post? Is it civil to comment anonymously? And so on.

Whereas the first issue is a more general academic problem, the second is specific to psychology and concerns the question whether or not direct replications have a role in social psychology, and if so when. As we have seen, some social psychologists resist the reforms because they do not think it is reasonable to demand that the results of social psychological experiments always be reproducible by following the description in the method section of the original report. Social behaviour is too sensitive to the social, cultural, and historical context, and this context too diverse and changeable, to expect this kind of stability. This issue is at once methodological and ontological: do Popper's rules of method apply in a field with a uniquely difficult object of research? And is that object really so unique? Ironically, it is precisely the direct replications and their recurring failure to reproduce earlier results that have 
provoked such questions about the appropriateness of a methodology in which direct replication is fundamental. Direct replications have been a disruptive force in psychology over the last six years, and in response arguments for a special status of social psychology, such as those of Crandall and Sherman and Stroebe, mentioned above, have been formulated. In fact, one could argue that the variability that they see as typical of social behaviour has been made visible by direct replications.

This ironic effect is a product of the reformers' emphasis on

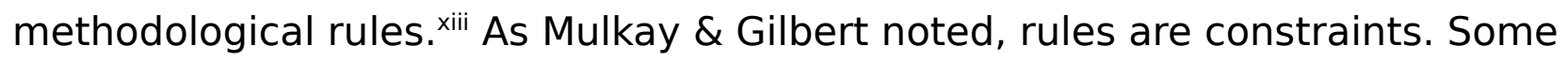
rules, however, are more constraining than others. Conceptual replication leaves the researcher more freedom than direct replication. In social psychology, that freedom has been used over the years in the production of sameness. By working on a high level of abstraction, that of the theory's constructs, researchers can claim that their studies provide evidence for the same general theory, even though what happens in the experiments is different in each case. Thus, variations in experimental procedures are used in the production of sameness. If this strategy is combined with publication bias against null-results, as has been the case for decades, the production of sameness is facilitated further, since falsifying instances never see the light of day. Alternatively, if experiments do not quite pan out as hypothesised, the theory may be amended by the addition of further variables (perhaps the relation only holds for women, or it requires a minimum level of anxiety). On this basis further hypotheses are tested, ${ }^{\text {xiv }}$ and again only the succesful studies are published. The result is a pattern that was noted (more or less simultaneously) by Paul Meehl (1990) and by Michael Billig (1990), namely that theories in social psychology tend to start out as bold statements of straightforward relations between a few variables, but then amass an increasing number of 'refinements' until they become so unwieldy that the field simply loses interest. All the while, the illusion of sameness is maintained, because although the theory gets more and more nuanced, incorporating more and more sources of variability, at some level it has remained the same, and it is shielded from falsification. Variability is never interesting in itself, except as a source of publications: research aims at finding the basic, underlying 
psychological processes that in conjunction with a changeable context 'produce behavior'. Nor is variability ever a risk, if only because the publication bias keeps failed studies well out of sight.

In contrast, in a research practice that puts direct replication up front variability can assert itself, as it were, on its own terms. It is precisely because researchers limit themselves to following the same procedure as an earlier experiment, that variability stands out as anomalous. Moreover, it is because researchers severely constrain their own freedom with methodological strictures like pre-registration, that variability may appear unimpeded. ${ }^{\mathrm{xv}}$ This is the irony of the reformers' emphasis on methodological rules: strict, direct replication, maximally constraining the experimenter, has produced disruptions, because it allows the object to object, to borrow a phrase from Latour (2000). Social psychology finds itself confronted with an epistemic device, direct replication, that over the last few years has regularly produced interesting differences in the form of non-replications. The ease of making such results public online offsets the publication bias of traditional peer reviewed journals and allows each non-replication to become a spectacle on social media, demanding a response from the original researchers and the field of social psychology in general.

\section{Conclusion: psychology's epistemic project}

The latest crisis in psychology has spawned a reform movement that is proposing thorough changes in psychology's epistemic practices, and is creating the sociotechnical conditions for what it sees as a better, more scientific psychology. Indeed, there is now a Society for the Improvement of Psychological Science (http://improvingpsych.org/), which meets yearly to discuss ideas for further changes in methods and practices. With its emphasis on hypothesis testing, direct replication, collaboration and open, critical debate, the reform program is distinctly Popperian, and proposals and arguments are frequently supported with references to Popper and like-minded philosophers of science such as Paul Meehl. Thus, the reformers stay well within the bounds of a rather traditional conception of science. Nonetheless, this effort to put Popper to work is innovative simply because such a strict 
adherence to these methodological principles has not been attempted before in psychology. Warnings about low power, publication bias, questionable research practices, and replication failures have been sounded before, but it is the first time these issues are addressed with such a comprehensive program of methodological reform.

Moreover, Popper may also turn out to be a source of renewal in spite of himself. As I've argued, direct replications have been a disruptive force in the discipline recently, regularly producing results that are so different from those of the original study that fundamental questions are raised not only about methodological and statistical practices, but increasingly also about the object of study itself. Critics of the reform movement have countered its proposals and projects with the argument that people are intensely context-sensitive beings in an extremely variable and changeable environment. "In matters of social psychology, one can never step in the same river twice", as Crandall and Sherman (2016, p. 94) put it. During the previous crisis in psychology, Ken Gergen argued something very similar, but he drew from this the conclusion that social psychology is a form of history and should let go of its ambition to be a natural science (Gergen, 1973). As yet, this is a step that critics of the reform movement are unwilling to take. Behind the variable and diverse behaviour they still presume to lie a stable, universal cognitive mechanism, which will ultimately be described by theories that are built and tested by doing conceptual replications. This makes social psychology a highly theoretical field, however, with no clear relevance for practice. xvi Such a retreat into abstraction may not be to everyone's liking, and as non-replications keep piling up, putting the robustness of results in doubt, some may choose to look for different approaches altogether, away from quantitative methods and a search for causal laws. They will ask a question that is largely absent from the current crisis debate: what is psychology good for? And are quantitative methods and experiments always the best way to bring it about? 


\section{Bibliography}

Baker, G., \& Hacker, P. (1985). Wittgenstein: rules, grammar and necessity. Oxford: Basil Blackwell.

Billig, M. (1990). Rhetoric of social psychology. In J. Shotter \& I. Parker (Eds.), Deconstructing social psychology (pp. 47-60). London: Routledge.

Bishop, D. V. (2013, July 26). Why we need pre-registration. Retrieved June 8, 2017, from http://deevybee.blogspot.nl/2013/07/why-we-need-preregistration.html

Bohannon, J. (2014). Replication effort provokes praise-and 'bullying' charges. Science, 344(6186), 788-789.

https://doi.org/10.1126/science.344.6186.788

Chambers, C. (2017a). The Seven Deadly Sins of Psychology: A Manifesto for Reforming the Culture of Scientific Practice. Princeton, NJ: Princeton University Press.

Chambers, C. (2017b, August 5). Why I hate the 'tone debate' in psychology and you should too. Retrieved from http://neurochambers.blogspot.com/2017/08/why-i-hate-tone-debate-inpsychology.html

Chambers, C. D. (2013). Registered Reports: A new publishing initiative at Cortex. Cortex, 49(3), 609-610. https://doi.org/10.1016/j.cortex.2012.12.016

Collaboration, O. S. (2015). Estimating the reproducibility of psychological science. Science, 349(6251), aac4716. https://doi.org/10.1126/science.aac4716

Crandall, C. S., \& Sherman, J. W. (2016). On the scientific superiority of conceptual replications for scientific progress. Journal of Experimental Social Psychology, 66, 93-99. https://doi.org/10.1016/j.jesp.2015.10.002 
Derksen, M. (2017). Histories of Human Engineering: tact and technology.

Cambridge: Cambridge University Press. Retrieved from https://doi.org/10.1017/9781107414921

Donnellan, B. (2013, December 11). Go Big or Go Home - A Recent Replication Attempt. Retrieved March 4, 2015, from https://traitstate.wordpress.com/ 2013/12/11/go-big-or-go-home-a-recent-replication-attempt/

Earp, B., \& Trafimow, D. (2015). Replication, falsification, and the crisis of confidence in social psychology. Frontiers in Psychology, 6. https://doi.org/10.3389/fpsyg.2015.00621

Ebersole, C. R., Atherton, O. E., Belanger, A. L., Skulborstad, H. M., Allen, J. M., Banks, J. B., ... Nosek, B. A. (2016). Many Labs 3: Evaluating participant pool quality across the academic semester via replication. Journal of Experimental Social Psychology, 67, 68-82. https://doi.org/10.1016/j.jesp.2015.10.012

Ferguson, C. J., \& Heene, M. (2012). A Vast Graveyard of Undead Theories: Publication Bias and Psychological Science's Aversion to the Null. Perspectives on Psychological Science, 7(6), 555-561.

Finkel, E. J., Eastwick, P. W., \& Reis, H. T. (2015). Best research practices in psychology: Illustrating epistemological and pragmatic considerations with the case of relationship science. Journal of Personality and Social Psychology, 108(2), 275-297. https://doi.org/10.1037/pspi0000007

Fiske, S. T. (2016a, September 19). Mob Rule or Wisdom of Crowds?

Fiske, S. T. (2016b, November 1). A Call to Change Science's Culture of Shaming. Retrieved November 2, 2016, from http://www.psychologicalscience.org/publications/observer/2016/nov-16/ a-call-to-change-sciences-culture-of-shaming.html

Gelman, A. (2016, September 21). What has happened down here is the winds have changed. Retrieved April 6, 2017, from 
http://andrewgelman.com/2016/09/21/what-has-happened-down-here-isthe-winds-have-changed/

Gergen, K. (1973). Social psychology as history. Journal of Personality and Social Psychology, 26(2), 309-320.

Gilbert, D. (2014, May 24). Psychology's replication police prove to be shameless little bullies: http://www.psychol.cam.ac.uk/cece/blog (corrected link) [microblog]. Retrieved May 19, 2017, from https://twitter.com/dantgilbert/status/470199929626193921?lang=en

Gilbert, D. T., King, G., Pettigrew, S., \& Wilson, T. D. (2016). Comment on "Estimating the reproducibility of psychological science." Science, 351(6277), 1037-1037. https://doi.org/10.1126/science.aad7243

Gilbert, N., \& Mulkay, M. J. (1984). Opening Pandora's box: a sociological analysis of scientists' discourse. Cambridge: Cambridge University Press. Retrieved from http://catdir.loc.gov/catdir/enhancements/fy0913/83005338-d.html Hamlin, J. K. (2017). Is Psychology Moving in the Right Direction? An Analysis of the Evidentiary Value Movement. Perspectives on Psychological Science, 1745691616689062. https://doi.org/10.1177/1745691616689062

Heino, M. (2017, June 2). Replication is impossible, falsification unnecessary and truth lies in published articles (?). Retrieved June 21, 2017, from https://mattiheino.com/2017/06/02/replication-is-impossible/

Iso-Ahola, S. E. (2017). Reproducibility in Psychological Science: When Do Psychological Phenomena Exist? Frontiers in Psychology, 8. https://doi.org/10.3389/fpsyg.2017.00879

Johnson, D. J., Cheung, F., \& Donnellan, M. B. (2014). Does Cleanliness Influence Moral Judgments? Social Psychology, 45(3), 209-215. https://doi.org/10.1027/1864-9335/a000186

Kahneman, D. (n.d.). Kahneman Commentary. Retrieved from http://www.scribd.com/doc/225285909/Kahneman-Commentary 
Kerr, N. L. (1998). HARKing: Hypothesizing After the Results are Known.

Personality and Social Psychology Review, 2(3), 196-217. https://doi.org/ 10.1207/s15327957pspr0203_4

Klein, R. A., Ratliff, K. A., Vianello, M., Adams Jr., R. B., Bahník, Š., Bernstein, M. J., ... Nosek, B. A. (2014). Investigating variation in replicability: A “many labs" replication project. Social Psychology, 45(3), 142-152. https://doi.org/10.1027/1864-9335/a000178

Kripke, S. A. (1982). Wittgenstein on rules and private language : an elementary exposition. Cambridge, MA: Harvard University Press.

Lakens, D. (2017a, June 19). Verisimilitude, Belief, and Progress in Psychological Science. Retrieved June 19, 2017, from http://daniellakens.blogspot.com/ 2017/06/verisimilitude-belief-and-progress-in.html

Lakens, D. (2017b, July 9). But just think of the number of years you'll benefit from having read this must-read book.https://twitter.com/beercatphd/status/884079663164801025 ... [microblog]. Retrieved from https://twitter.com/lakens/status/884081460319322112?s=09

Latour, B. (2000). When things strike back: a possible contribution of "science studies" to the social sciences. British Journal Of Sociology, 51(1), 107123.

LeBel, E. P. (2017, May 18). The Language of Science: A Primer. Retrieved May 19, 2017, from https://proveyourselfwrong.wordpress.com/2017/05/18/the-language-ofscience-a-primer/

LeBel, E. P., Berger, D., Campbell, L., \& Loving, T. J. (2017, May 13). Falsifiability is not optional. Retrieved from osf.io/preprints/psyarxiv/dv94b

LeBel, E. P., \& Peters, K. R. (2011). Fearing the future of empirical psychology: Bem's (2011) evidence of psi as a case study of deficiencies in modal 
research practice. Review of General Psychology, 15(4), 371-379. https:// doi.org/10.1037/a0025172

Ledgerwood, A. (2017, January 24). Why the F*ck I Waste My Time Worrying about Equality [Incurably Nuanced]. Retrieved August 15, 2017, from http://incurablynuanced.blogspot.com/2017/01/inequality-in-science.html Lieberman. (2014, 8). Latitudes of Acceptance. A conversation with Matthew D. Lieberman. Edge.Org. Retrieved from http://edge.org/conversation/latitudes-of-acceptance

Meehl, P. E. (1990). Appraising and Amending Theories: The Strategy of Lakatosian Defense and Two Principles that Warrant It. Psychological Inquiry, 1(2), 108-141. https://doi.org/10.1207/s15327965pli0102_1

Mulkay, M., \& Gilbert, G. N. (1981). Putting Philosophy to Work: Karl Popper's Influence on Scientific Practice. Philosophy of the Social Sciences, 11(3), 389-407. https://doi.org/10.1177/004839318101100306

Neuroskeptic. (2013, April 25). For Preregistration in Fundamental Research. Retrieved June 8, 2017, from http://blogs.discovermagazine.com/neuroskeptic/2013/04/25/forpreregistration-in-fundamental-research/

Pickering, A. (Ed.). (1992). Science as Practice and Culture. University of Chicago Press.

Popper, K. R. (1972). The logic of scientific discovery. London: Hutchinson.

Popper, K. R. (2002a). The logic of scientific discovery (2nd ed.). London: Taylor $\&$ Francis.

Popper, K. R. (2002b). The Open Society and Its Enemies. (7th ed.). London: Taylor \& Francis.

Promoting Open, Critical, Civil, and Inclusive Scientific Discourse in Psychology. (2016, September 30). Retrieved August 14, 2017, from http://www.spsp.org/blog/inclusive-scientific-discourse1 
Schepens, W. (1994, March 7). “Wat is wetenschap?" Noorderlicht. Hilversum: VPRO. Retrieved from https://www.youtube.com/watch?v=uNrNZqtTdvA Schnall, S. (2014a). Moral Intuitions, Replication, and the Scientific Study of Human Nature. Presented at the Headcon '14. Retrieved from http://edge.org/conversation/simone-schnall-moral-intuitions-replicationand-the-scientific-study-of-human-nature

Schnall, S. (2014b, May 23). An Experience with a Registered Replication Project. Retrieved May 25, 2014, from http://www.spspblog.org/simoneschnall-on-her-experience-with-a-registered-replication-project/

Schnall, S., Benton, J., \& Harvey, S. (2008). With a clean conscience: cleanliness reduces the severity of moral judgments. Psychological Science, 19(12), 1219-1222. https://doi.org/10.1111/j.1467-9280.2008.02227.x

Schwarzkopf, S. (2017, August 7). Is open science tone deaf? Retrieved from https://neuroneurotic.net/2017/08/07/is-open-science-tone-deaf/

Simmons, J. P., Nelson, L. D., \& Simonsohn, U. (2011). False-Positive Psychology. Psychological Science, 22(11), 1359-1366. https://doi.org/10.1177/0956797611417632

Spellman, B. A. (2015). A Short (Personal) Future History of Revolution 2.0.

Perspectives on Psychological Science, 10(6), 886-899. https://doi.org/10.1177/1745691615609918

Srivastava, S. (2014a, July 1). Some thoughts on replication and falsifiability: Is this a chance to do better? Retrieved June 5, 2015, from https://hardsci.wordpress.com/2014/07/01/some-thoughts-on-replicationand-falsifiability-is-this-a-chance-to-do-better/

Srivastava, S. (2014b, November 19). Popper on direct replication, tacit knowledge, and theory construction. Retrieved June 5, 2015, from https:// hardsci.wordpress.com/2014/11/19/popper-on-direct-replication-tacitknowledge-and-theory-construction/ 
Srivastava, S. (2015, March 12). An open review of Many Labs 3: Much to learn. Retrieved March 16, 2015, from https://hardsci.wordpress.com/2015/03/12/an-open-review-of-many-labs3-much-to-learn/

Srivastava, S. (2017, July 13). I asked my lab what do you want to do this summer. They said let's nerd out of philosophy and statistics together. I love my labpic.twitter.com/NjUMM6xt3x [microblog]. Retrieved from https://twitter.com/hardsci/status/885542833771298816

Strack, F. (2017). From Data to Truth in Psychological Science. A Personal Perspective. Frontiers in Psychology, 8. https://doi.org/10.3389/fpsyg.2017.00702

Stroebe, W. (2016). Are most published social psychological findings false? Journal of Experimental Social Psychology, 66, 134-144. https://doi.org/10.1016/j.jesp.2015.09.017

Stroebe, W., \& Strack, F. (2014). The Alleged Crisis and the Illusion of Exact Replication. Perspectives on Psychological Science, 9(1), 59-71. https://doi.org/10.1177/1745691613514450

Wagenmakers, E.-J., Beek, T., Dijkhoff, L., Gronau, Q. F., Acosta, A., Adams, R. B., ... Zwaan, R. A. (2016). Registered Replication Report: Strack, Martin, \& Stepper (1988). Perspectives on Psychological Science. https://doi.org/ $10.1177 / 1745691616674458$

Wagenmakers, E.-J., Wetzels, R., Borsboom, D., Maas, H. L. J. van der, \& Kievit, R. A. (2012). An Agenda for Purely Confirmatory Research. Perspectives on Psychological Science, 7(6), 632-638. https://doi.org/10.1177/1745691612463078

Wilson, A. (2014, May 26). Psychology's real replication problem: our Methods sections. Retrieved May 27, 2014, from http://psychsciencenotes.blogspot.co.uk/2014/05/psychologys-realreplication-problem.html 
Yarkoni, T. (2016, October 1). There is no "tone" problem in psychology. Retrieved from https://www.talyarkoni.org/blog/2016/10/01/there-is-notone-problem-in-psychology/ 
i Finkel, Eastwick and Reis (2015) and Hamlin (2017) recently used the term "evidentiary value movement". I will use 'reform movement', 'reformers' and 'critics'.

ii Brian Earp and David Trafimow speak of "a widespread if vague allegiance to Popperian ideals in contemporary scientists" (Earp \& Trafimow, 2015, p. 1).

iii Mulkay and Gilbert are speaking specifically about publication practices here, but use them as an example of a more general point about the link between rules and actions.

iv Whether there 'really is' a crisis in psychology is itself contested; Stroebe \& Strack (2014) for example contest it. For the purposes of this article I will define the 'reform movement' as those people who believe there is a crisis, and take part in the discussions about it and/or the practical initiatives to solve it. There are no firm boundaries, but, as will be discussed later, reformers connect in various ways, including social media and the infrastructure of the Open Science Framework. There now exists a Society for the Improement of Psychological Science (http://improvingpsych.org/), further institutionalising the movement.

$\checkmark$ An even more prominent topic of discussion is statistics. Statistical flaws, low power in particular, are seen as a major problem in psychology. More fundamentally the reliance on null hypothesis significance testing is seen by some as a basic flaw.

vi "Although everybody had heard of Popper, very few have actually read him." (Mulkay \& Gilbert, 1981, p. 393)

vii This conclusion was contested by Gilbert et al. (2016).

viii Iso-Ahola (2017) also disputes the necessity of falsification.

ix See e.g. Bohannon (2014) for a brief report.

$x$ A recent example is the discussion about a large-scale replication effort testing the 'facial feedback hypothesis' (Strack, 2017; E.-J. Wagenmakers et al., 2016).

xi LeBel et al.'s paper is titled 'falsifiability is not optional'. That direct replication is fundamental is also argued by Heino (2017)

xii For example, Popper's discussion of probability in The Logic of Scientific Discovery is mostly ignored. Only Daniel Lakens (2017a) has referred to it.

xiii In what follows I build on an argument I presented in chapter 9 of Histories of Human Engineering (Derksen, 2017).

$x i v$ At least, that is the way research should proceed. In practice, HARKing is common.

xv See also Srivastava (2014a) about (direct) replication as a route to discovery.

xvi Crandall and Sherman (2016), like Stroebe and Strack (2014), acknowledge that direct replications are important in an applied context, where interventions need to reliably produce the same effect. They do not explain why direct replications would be more likely to succeed outside the laboratory. 